\section{O discurso cinematográfico sobre Brasília e a ideologia desenvolvimentista}

\section{Cinematic discourse on Brasília and developmentalist ideology}

\section{João Gabriel de Oliveira}

Universidade de Brasília. Instituto de Psicologia.

\section{RESUMO}

A produção audiovisual sobre Brasília, importante veículo ideológico do nacional-desenvolvimentismo, passa a criticar este projeto nas décadas de 1960 e 1970. Relacionando cinema, história e o debate sobre Teoria Marxista da Dependência, as limitações do projeto desenvolvimentista são discutidas.

PALAVRAS-CHAVE: cinema candango, história de Brasília, desenvolvimentismo; Teoria Marxista da Dependência, ideologia. KEYWORDS: candango cinema, history of brasilia, national-developmentalism;

\section{ABSTRACT}

Film production about Brasilia, previously an important vehicle of nationaldevelopmentalist ideology, started taking a critical stance on this project since the 1960s. Articulating history, film analysis and the debate on the Marxist Theory of Dependency, the limits of developmentalism are discussed.

Marxist Theory of Dependency, ideology.
"Nunca houve um monumento da cultura que não fosse também um monumento da barbárie." (BENJAMIN, 1994, p. 225)

\section{INTRODUÇÃO - POR QUE BRASÍLIA?}

Dentre todas as cidades brasileiras, é possível que Brasília seja campeã em termos de mitos, fábulas, mistificações sobre sua criação.

O historiador Hermes Aquino Teixeira, em sua dissertação "Brasília: o outro lado da utopia"(1956-1960) (TEIXEIRA, 1982), explicita muito bem os obstáculos que alguém que se propõe a fazer um resgate historiográfico sobre a capital federal irá enfrentar. Para além do descaso à memória histórica na preservação precária ou até mesmo na destruição literal de documentos valiosos para a reconstrução desse passado, o autor aponta a escassez de estudos críticos sobre a história de Brasília. Prevalecem, em vez disso, documentos escritos por figuras que ocuparam importantes cargos gerenciais e econômicos na construção da capital, muitas vezes em formatos memorialísticos e sem uma metodologia historiográfica compreensiva e consistente, ecoando um discurso oficial profundamente ideológico.

Mas qual a relação entre o cinema, a ideologia desenvolvimentista e a história de Brasília? Embora a compreensão completa dessa inter-relação demande um desenvolvimento mais longo, o seguinte apontamento de Vladimir Carvalho, figura fundamental do cinema brasiliense, é um bom ponto de partida:

"O cinema foi uma presença marcante em Brasília desde a fase pioneira da construção da nova capital. Fosse pelo funcionamento algo rústico de "cinemas" ao ar livre com que se entretia a grande massa de trabalhadores nos momentos de folga, fosse pela presença mesma de grande número de cinegrafistas que trabalhavam para os cinejornais, documentando as visitas do presidente Juscelino Kubitscheck e de outros chefes de estado. Pode-se mesmo dizer que Brasília veio à 
luz sendo partejada pelo cinema. Nesse sentido, ela também é única no mundo: o cinema tem aqui a mesma idade da capital." (CARVALHO, 2002, p. 19)

A transferência da capital para Brasília foi discutida desde o Século XIX, e a partir de 1922 passou a figurar como dispositivo constitucional. O debate sobre esta interiorização tem períodos de ressurgência irregulares ao longo da história brasileira, mas os principais argumentos para a mudança foram de ordem geopolítica - com a finalidade de impedir ataques de potências navais militarmente superiores - ou de explorar economicamente essa vasta região do interior. Entretanto, embora tivesse força de lei, a proposta da mudança da capital só se materializou quando presidente Juscelino Kubitschek incorporou essa mudança em seu Programa de Metas, base de sua campanha eleitoral de 1956. Como ele próprio anunciou na ocasião do discurso inaugural da Brasília, proferido em 21 de abril de 1960:

“No programa de metas do meu Governo, a construção da nova Capital representou o estabelecimento de um núcleo, em torno do qual se vão processar inúmeras realizações outras, que ninguém negará fecundas em conseqüências benéficas para a unidade e a prosperidade do País." (KUBITSCHECK, 1960/2009, p. 52)

Demonstrada a importância do estabelecimento de Brasília como núcleo do Plano de Metas, cabe agora avaliar o conteúdo do projeto nacional-desenvolvimentista que ele preconizava, contextualizando-o a partir do debate teórico sobre a condição de subdesenvolvimento que ocorria no Brasil na época.

A principal organização que fomentou o pensamento desenvolvimentista na América Latina foi a Comissão Econômica para a América Latina (CEPAL), que produziu estudos econômicos com o intuito de superar as barreiras ao desenvolvimento, apontando a industrialização como o elemento chave para a superação do atraso nas América Latina, cuja economia era tida como muito especializada e voltada para exportação (DOS SANTOS, 2000). Entretanto, o autor demonstra que a burguesia 52 industrial brasileira, que surgiu diante dos processos de substituição de importação em momentos de crise no capitalismo global (como as Guerras Mundiais e a Crise de 1929), dependia fortemente de divisas oriundas do setor agrário exportador. A partir do momento em que o capitalismo mundial foi reorganizado através da hegemonia estadunidense (após a Segunda Guerra Mundial), houve um fluxo de capital internacional que buscou ultrapassar as barreiras alfandegárias latino americanas, se voltando para o investimento em manufaturas destes países dependentes como forma de se voltar aos seus mercado internos.

Entretanto, Teixeira (1982) aponta que este discurso de ampliar o mercado interno e expandir a indústria acabou por ocultar a dependência histórica do bloco industrial-rural em relação aos centros hegemônicos do capitalismo. Dessa forma, o mecanismo de industrialização acelerada para assentar o progresso da nação, de "50 Anos em 5", implicou medidas de facilitação do fluxo de capitais estrangeiros através de concessões tarifárias, creditícias, fiscais e até mesmo na introdução no país de maquinários que já eram obsoletas nos centros capitalistas. Apesar da introdução de um novo maquinário ter modificado a composição orgânica do capital brasileiro, maximizando nossa potencialidade industrial, isso não foi suficiente para minimizar a transferência de valor para os centros do capitalismo, dado estrutural na realidade do capitalismo dependente, visto que o setor industrial brasileiro permaneceu com baixa produtividade relação aos países centrais, com suas tecnologias mais avançadas e monopólios (MARINI, 1973).

A construção de Brasília foi o baluarte ideológico e síntese desse plano de "50 Anos em 5", o que facilitou fluxos de capital estrangeiro para os setores de construção civil e da indústria automotiva, motivando uma expansão das malhas rodoviária e alimentando um estado particular de euforia popular (TEIXEIRA, 1982). Foi criado um forte sentimento de que todos seriam beneficiados pela construção desta capital, 
o que motivou uma intensa migração interna oriunda principalmente do Nordeste, região que passava por sérias crises naquele período.

Portanto, a escolha do caso singular de Brasília e seu cinema para pensar a questão mais universal do subdesenvolvimento no Brasil e na América Latina não é incidental. Como apontou o jornalista Pompeu de Sousa em entrevista à Vladimir Carvalho, (...) Brasília é um microcosmo em relação ao macrocosmo que é Rio e São Paulo. Então, Brasília passou a dar um close-up. Um close-up da miséria brasileira. E então a utopia da "Capital da Esperança" se transformou na realidade de Capital do Desespero Nacional, que deu à essa nação a substituição da utopia pela realidade (CARVALHO, 1997, p. 361)

\section{DE CERRADO A EL DORADO: O CINEMA E A FORMAÇÃO DO MITO}

Para tratar do cinema nascente na capital federal, Moriconi (2012) recorrea uma divisão interessante: o da "ficção onírica" e do "real onírico". O primeiro período corresponde a quando dois cineastas estrangeiros, Marcel Camus e Philippe de Broca, buscaram no caráter moderno e insólito da cidade em construção um espaço para dois longas metragens em que predominaram a projeção de idealizações estrangeiras sobre esta capital. Já no período do "real onírico", os primórdios da fabricação ideológica da utopia Brasília, o autor localiza os esforços de alguns dos primeiros cinematógrafos como José e Sálvio da Silva, que tinham bastante proximidade com Juscelino e foram contratados por seu braço direito Israel Pinheiro, diretor da Companhia Urbanizadora da Nova Capital do Brasil (NOVACAP), para capturar alguns dos primeiros registros da construção. Entretanto, a figura que é mais lembrada na história como cinematógrafo da construção brasiliense é o fotojornalista e produtor francês Jean Manzon, que radicou-se no Brasil e desempenhou vários trabalhos no jornalismo e tem uma longa trajetória em filmes publicitários.
Aqui, o cinema de Jean Manzon foi escolhido como referência principal para analisar o conteúdo da ideologia nacional-desenvolvimentista no cinema tanto devido a sua ampla difusão (como filme-jornais; essas peças publicitárias atingiam todos os cantos do país), quanto devido à maneira inequívoca que sua obra responde aos interesses diretos do bloco agrário-industrial nos períodos da Década de 1950 e 1960. Isso se dá tanto pela maneira que ele mobiliza a iconografia do nacionaldesenvolvimentismo (setores industrialistas, veículos, operários) quanto pela sua forma de utilizar a linguagem cinematográfica no intuito de criar uma identificação entre os objetivos desenvolvimentistas da burguesia industrial brasileira e os desejos e anseios da classe trabalhadora, não obstante a contradição estrutural de interesses entre estes grupos sociais.

Em "As primeiras imagens de Brasília" (MANZON, 1957), somos apresentados a sequências de imagens aéreas do processo de construção da cidade. A trilha sonora é erudita e imponente, e a estes planos longos e épicos é sobreposta uma narração em voice-over exaltando triunfalmente a empreitada mudancista. Todos os elementos operam no sentido de elevar a capital nascente ao estatuto de mito. Brasília é exaltada como "Cidade do Futuro", e a voz que diz isso, grave e tão grandiosa quanto os planos aéreos dos primeiros momentos da construção do Palácio do Planalto, não coincidentemente pertence a Luiz Jatobá, popularmente conhecido como a "Voz do Brasil" por ter sido responsável pelas coberturas radiofônicas da transmissão governamental da Hora do Brasil por 45 anos. Em uma terra desbravada em que "o trabalho desconhece a noite" e "a idade da técnica encontra a idade da harmonia", essa nova capital é elevada como um farol para "os longos caminhos da nova civilização brasileira".

Já o filme-jornal "Coluna Norte" (MANZON, 1960) é ainda mais rico em representações dessa ideologia. Sua cobertura da construção da Rodovia Belém-Brasília, que 
promovia o fluxo dos trabalhadores nordestinos para o Planalto Central, além de repetir as convenções do filme anterior de uma maneira que beira o formulaico, possui prevalência maior de registros da expansão rodoviária brasileira, uma das bases do Programa de Metas de Juscelino Kubitscheck, que além da mobilização do setor da construção civil também promoveu a indústria automobilística. O caráter apelativo ao trabalhador é aqui ainda mais claro. Seu tratamento é repleto de vocativos de exaltação: "Pioneiros, ó pioneiros", diz a voz de Jatobá, caracterizando Brasília como um "lugar de harmonia entre os povos do Sul e do Norte", em que esta classe desbravadora, de "Jovens do Oeste", encontraria riquezas e forjaria o desenvolvimento do povo brasileiro a partir do trabalho incansável, gerando, assim, o espírito do progresso. Dois momentos específicos deste filme merecem destaque. Primeiro, a simbologia sacrossanta empregada quando Manzon aborda a morte de Bernardo Sayão, engenheiro da NOVACAP morto em um acidente de trabalho durante a construção da estrada. Em uma história tão repleta de candangos mortos e apagados historicamente, é muito significativo o contraste entre a morte em massa dos pioneiros desconhecidos e a tratamento transcendental da morte de Sayão, narrada como o sacrifício de um grande homem pelo progresso. Em meio a imagens do enterro de Sayão, a voz de Jatobá, com seu eco lúgubre característico, se dirige aos candangos em uma maneira que beira o premonitório: "marchando é que morremos mais dignamente, Pioneiros, ó Pioneiros".

Em segundo, façamos uma decupagem dos últimos dois planos do filme. O registro inicia com um plano da chegada de Juscelino Kubitscheck no Planalto Central à bordo da chamada "Caravana da Integração Nacional". Ele é felicitado, e bandeiras tremulam enquanto ele chega ao que hoje é a Praça dos Três Poderes. Destaca-se, no último plano, principalmente, a sobreposição imagética entre o Palácio do Planalto, de fundo, e um batalhão de ônibus Mercedez-Benz seguindo em direção da câmera no primeiro plano, num percurso que se estende para além do enquadramento: uma encenação simbólica do progresso nacional-desenvolvimentista, cuja representação simbólica desconhece molduras, barreiras e limites e cuja estética está diretamente atrelada a pressupostos altamente ideológicos. Como nos lembra Xavier (2005), vemos aqui "a inscrição do cinema (como forma de discurso) dentro dos limites definidos por uma estética dominante, de modo a cumprir através dele necessidades correlatas aos interesses da classe dominante" (XAVIER, 2005, p. 38).

A crítica ao "nacional- desenvolvimentismo" no cinema pós-inauguração a partir do início da Década de 1960, ou seja, após a inauguração da cidade, é possível observar o surgimento de um cinema mais crítico acerca dos pressupostos ideológicos e intenções políticas que orientavam a produção cinematográfica em Brasília até então. É possível compreender esta mudança se analisarmos os vários acontecimentos culturais relevantes que ocorriam no Brasil ao longo deste período.

Em primeiro lugar, despontava no Brasil e no mundo o Cinema Novo, movimento que efetivamente exportou o cinema brasileiro e trouxe diversas inovações técnicas e críticas, com diretores que chegaram a utilizar todo este repertório novo de fazer cinema na própria capital federal (como foi o caso de Nelson Pereira dos Santos, Joaquim Pedro de Andrade e Glauber Rocha). Na década de 1960 também foi fundada também a Universidade de Brasília, que surge a partir de um plano revolucionário do antropólogo Darcy Ribeiro e do educador Anísio Teixeira. Seu curso de cinema foi pioneiro no Brasil, organizado por figuras de renome como Paulo Emílio Salles Gomes, Jean Claude Bernardet, Dib Lutfi e Nelson Pereira dos Santos. Além disso, após a repressão ao corpo docente e discente da universidade e da demissão de grande parte do corpo docente em 1965, que levou à desestruturação deste núcleo cinematográfico, houve uma reestruturação da produção cinematográfica da Universidade de Brasília que ocorreu a partir da Década de 1970, selando a inclinação 
documental que perpassa o cinema candango desde então (MORICONI, 2012). Para iniciar um debate sobre a crítica à mistificação brasiliense no cinema, escolhi três filmes fundamentais deste período crítico: "Fala Brasília” (1966), “Brasília: contradições de uma cidade nova" (1967) e "Brasília segundo Feldman” (1979).

Em "Fala Brasília" (SANTOS, 1966), dirigido e montado por Nelson Pereira dos Santos e com fotografia de Dib Lutfi, temos umas a amostra pioneira de um olhar menos ideológico sobre Brasília. Desdobramento direto do ethos cultural de uma Universidade de Brasília nascente, os créditos iniciais deste curta-metragem já informam que a obra surge a partir de uma pesquisa dialetológica. Dado que Brasília se constitui através de um enorme fluxo migratório interno, o filme aborda os diferentes falares regionais dos trabalhadores que pertenciam à primeira geração de brasilienses. Nesse contexto, a pesquisa dialetológica orientada pelo linguista e professor universitário Nelson Rossi serve como prerrogativa para a criação de um retrato das mãos que desde 1960 edificam a capital em que, momentaneamente, foram depositadas esperanças de progresso e redenção nacional. Podemos dividir o filme em duas partes.

Na primeira, ambientada na Rodoviária, uma região chave para ofluxo de trabalhadores de todas as regiões administrativas adjacentes ao Plano Piloto até a atualidade, somos apresentados a trabalhadores diversos, oriundos de vários estados brasileiros. São estes: Pará, Amazonas, Alagoas, Ceará, Pernambuco, Rio Grande do Norte, Espírito Santo, Minas Gerais, Rio de Janeiro, Paraná, Mato Grosso, Santa Catarina, São Paulo, Rio Grande do Sul, Goiás, Minas Gerais e Bahia.

Os entrevistados trazem à tona pensamentos diversos acerca do próprio trabalho, de sua condição em Brasília e suas aspirações. Destaca-se neste momento do filme a baixa interferência do documentarista/entrevistador no processo da entrevista. Há momentos em que vemos os trabalhadores conversando entre si, se interpelando e se complementando em um processo dialógico que aponta que a experiência de Brasília é muito mais complexa e multideterminada do que os ideólogos da "Capital da Esperança" fizeram parecer no princípio da década. A partir da voz dos trabalhadores somos apresentados à força da publicidade que os trouxeram para esta cidade, às suas formas de inserção nesse contexto social e ao contraste entre as experiências da população oriunda das regiões Sudeste e Sul, sobretudo servidores públicos membros das camadas médias, e das denúncias de extenuantes horas de trabalho por parte da população oriunda do Norte e Nordeste, que compuseram a maioria do contingente migratório de Brasília.

Na segunda parte do filme, percebemos uma ruptura inicial a partir de sua ambientação nova: filmado na Concha Acústica, um teatro à céu aberto com arquitetura marcadamente modernista e minimalista no centro de Brasília, percebese um contraste claro em relação ao caráter dinâmico e populoso da rodoviária. Aqui, o grupo de entrevistados reduz-se a cinco: cada um representante de uma região brasileira. A fotografia de Dib Lutfi atinge seu nível máximo de criatividade enquanto enquadra estes trabalhadores sobrepostos às estruturas de concreto do teatro, originando planos que destacam a qualidade moderna da arquitetura e intrigantes jogos de sombra que se contrapõe sensivelmente ao caráter naturalista e discreto que o trabalho de câmera assume na primeira parte. Os trabalhadores, então, se dirigem à câmera detalhando como foram interpelados a participar da pesquisa pelos documentaristas. No momento final, cada entrevistador lê uma lista de palavras idêntica, e a através do recurso da montagem e da organização contígua das mesmas palavras pronunciadas por pessoas de regiões distintas, somos levados a perceber as diferenças dos falares regionais e o pluralidade das vozes que formaram a cidade e, até a atualidade, a constituem diariamente.

Em "Brasília: contradições de uma cidade nova" (ANDRADE, 1967) temos um processo 
de planejamento e escopo distinto do caráter eminentemente acadêmico que fomentou a produção do filme anterior. Este curta-metragem de Joaquim Pedro de Andrade foi feito por encomenda da empresa Olivetti, e devido ao seu caráter crítico foi rejeitado e engavetado por seus financiadores. Diante disso, antes mesmo de submetê-lo à censura para ser avaliado, o diretor exibiu o filme no Festival de Cinema de Brasília e chegou até mesmo a receber premiação (SILVA, 2019).

O curta é narrado pelo poeta Ferreira Gullar, e sua estruturação é marcadamente dialética. Sua tentativa de estabelecer uma perspectiva crítica envolve, portanto, uma captura do caráter eminentemente contraditório da empreitada Brasília. Podemos notar delimitar três momentos distintos em sua construção, em que somos exibidos à cidade em suas diversas dimensões, que poderiam ser descritas como: (1) Brasília como utopia da modernidade, (2) Brasília em sua realidade contraditória, e (3) Brasília como possibilidade.

No primeiro momento, somos apresentados às dimensões idealistas que fomentaram o plano-piloto de urbanização da cidade. O tom imponente das filmagens aéreas e grandiosas dos filme-jornais de Jean Manzon são substituídos por uma prevalência de planos mais chãos, marcados tanto por movimentos de câmera situados em um nível de altura mais próximo a do ponto de vista de uma pessoa que anda pela cidade e seus comércios nascentes quanto pela utilização da câmera em travellings, em que acompanhamos a visão de um automóvel que desvela as particularidades desta capital indissociável de um certo imaginário dinâmico, industrial e automobilístico do nacional-desenvolvimentismo. A trilha sonora é a principal responsável pelo estabelecimento do caráter utópico do projeto brasilense neste documentário. Aqui, os sonhos de criar uma capital bela e funcional, farol do desenvolvimento em que as diferenças de classe são dissolvidas pela convivência comum e harmoniosa em um projeto urbanista minuciosamente planejado são apoiados no caráter onírico da peça "Gymnopédie Pt. 1", do compositor francês Erik Satie.

Na segunda parte, há uma ruptura do caráter harmonioso e onírico que a peça musical anterior sugere. Em meio a imagens de uma feira de rolo em uma região periférica de Brasília, o cotidiano dos trabalhadores que edificaram a capital é enquadrado a partir de músicas regionais nordestinas, e, em suas entrevistas, esses trabalhadores revelam os diversos suplícios da experiência de marginalização e exploração que permeia seus cotidianos. Essa maioria populacional, visto que mais de $2 / 3$ da população daquele período habitava fora de região central retratada na primeira parte do documentário, revelam a partir de entrevistas a longa viagem de ônibus até a região central, seus locais de trabalho, em gastam até três horas em um modelo precário de transporte público; o contraste entre o planejamento moderno verticalizado no urbanismo do centro e o caráter espontâneo, arcaico e horizontalizado das então chamadas "cidades-satélite" em que viviam; e das condições de trabalho extenuantes.

No terceiro e último momento, é a canção de protesto Viramundo que dá o tom do que poderia ser a cidade. A construção do filme espelha a composição engenhosa e dialética da canção escrita por Gilberto Gil e José Carlos Capinam e cantada aqui por Maria Bethânia. Como o eu lírico de "Viramundo" que "corta com faca e facão os desatinos da vida" e transforma um mundo "astuto, mal e ladrão" em "festa, trabalho e pão" (BETHÂNIA, 1965), contemplamos aqui a possibilidade de que, um dia, a população que edificou a capital possa, enfim, desfrutar dela. O filme apresenta diversos planos de obras modernistas monumentais como o Palácio do Planalto e o Congresso Nacional, concluindo ao som de "Viramundo", um plano composto por operários de construção civil trabalhando em uma obra de curvas suntuosas, sobrepondo antiteticamente a leveza de uma arquitetura moderna e a dureza do trabalho que a edificou. O monólogo de Ferreira Gullar prossegue:

"Brasília encarna o conflito básico da arte brasileira fora do alcance da maioria do 
povo. O plano dos arquitetos propôs uma cidade justa, sem discriminações sociais. Mas à medida que o plano se tornava realidade, os problemas cresciam para além das fronteiras urbanas em que se procurava conter. Na verdade são problemas nacionais, de todas as cidades brasileiras, que nessa, generosamente concebida, se revelam com insuportável clareza. É preciso mudar essa realidade para que se descubra no rosto do povo o quanto uma cidade pode ser bela." (ANDRADE, 1967) "Brasília Segundo Feldman" (CARVALHO, 1979), apesar de ser o filme mais recente abordado neste ensaio, é ambientado em 1959. A razão para o lapso de 20 anos entre a filmagem e o lançamento é o fato de que todas as suas imagens foram feitas por Eugene Feldman, um designer estadunidense que visitou Brasília nos momentos finais de sua construção, e foram recuperadas pelo documentarista Vladimir Carvalho já na Década de 1970 (MORICONI, 2012). Dessa forma, o trabalho é único no sentido de que a força criativa e crítica não são oriundos das imagens de Feldman por si só, mas do trabalho de montagem de Vladimir que, naquele momento combinou as imagens com o testemunho de duas figuras pioneiras na construção de Brasília: Athos Bulcão, pintor e paisagista, e Luiz Perseghini, ex-operário e sindicalista. Enquanto as figuras comentam as imagens, por diversos momentos seus discursos entram em contradição, demonstrando as tensões imanentes entre o discurso oficial sobre Brasília e a experiência vivida do ex-operário.

Em seus vinte minutos, o filme aborda em muitos níveis o descompasso discursivo entre o operário e o arquiteto, comentando assuntos que vão desde a alimentação e elementos cotidianos da construção até as condições de trabalho e expectativas relativas ao futuro da capital. Entretanto, seria um erro relativizar as diferenças entre a fala de Perseghini e Athos como diferentes narrativas igualmente válidas, haja vista que suas perspectivas apontam diferenças factuais muito marcantes. Por exemplo: enquanto Athos Bulcão admite que houve alguns acidentes de trabalho, a que ele atribui basicamente a falta de equipamentos e medidas de segurança por parte do operário, desresponsabilizando as construtoras e os órgãos estatais da garantia de segurança no trabalho, Perseghini aponta que diante do cotidiano de trabalho extenuante, em que se poderia passar dias e noites seguidos em cima de andaimes, acidentes não eram acontecimentos corriqueiros, mas fatos diários. Perseghini comenta que diante de acidentes comuns como a queda de andaimes, haviam equipes da NOVACAP à disposição para removerem os corpos prontamente no intuito de não atrapalharem o ritmo de trabalho. Aos familiares destes operários mortos não havia indenização, já que diante da parca documentação e da necessidade de não comprometer a imagem da empreitada mudancista muitos daqueles trabalhadores eram dados como desaparecidos.

Um dos pontos máximos de divergência entre o discurso oficial da fundação de Brasília e o relato dos operários também é retratado neste documentário: o massacre de operários no acampamento da construtora Pacheco Fernandes, empreendido pela Guarda Especial de Brasília (GEB). Como aponta Teixeira (1982), a GEB foi um órgão paramilitar que surgiu por iniciativa da NOVACAP para garantir o disciplinamento dos trabalhadores e efetivar a construção da capital no prazo estabelecido. No dia 8 de fevereiro de 1959, quando os trabalhadores da construtora protestaram contra as condições insalubres de sua alimentação, foram ameaçados por soldados da GEB que, em um momento posterior, voltaram ao acampamento com metralhadoras e dispararam rajadas de tiro contra os trabalhadores. Posteriormente, os corpos dos operários foram jogados em caminhões e enterrados em uma vala comum distante da cidade, até hoje não descoberta. Embora seja fato conhecido e comentado pelos pioneiros, até a atualidade há autoridades que negam veementemente a ocorrência deste evento. É o exemplo de Ernesto Silva, diretor da NOVACAP do período e escritor que, em entrevista à Vladimir Carvalho na ocasião da filmagem de outro documentário 
seu na Década de 1990, afirmou que a GEB foi acionada naquele momento diante de bebedeiras e badernas dos trabalhadores, ao mesmo tempo sustentando a tese de que não houve massacre algum (CARVALHO, 1997).

\section{CONCLUSÃO: QUAIS AS VIAS ABERTAS PARA A AMÉRICA LATINA?}

Neste ensaio, busquei relacionar as etapas iniciais da produção cinematográfica sobre Brasília com o contexto mais amplo do debate sobre a questão do subdesenvolvimento na América Latina. Lidar com tamanha amplitude temática implica, necessariamente, incorrer em um terreno multidisciplinar que origina várias determinações distintas, trazendo o risco que a necessidade de síntese se converta em simplificações que devem ser trabalhadas mais exaustivamente em suas particularidades e complexidades específicas em momentos futuros.

Dessa forma, estes apontamentos foram apenas um breve exercício para demonstrar a potencialidade que obras de arte tem de nos ajudar a "escovar a história a contrapelo", para utilizar a expressão de Benjamin (1994). A trajetória da produção cinematográfica de Brasília está inserida em um contexto muito mais amplo, do sistema de produção latino-americano e ainda da posição da América Latina na totalidade de um sistema mundial. Portanto, falar das particularidades do cinema brasiliense pode ser um caminho para pensar dinâmicas mais globais da arte cinematográfica diante do capitalismo dependente, realidade comum em que os países latino americanos estão inseridos.

Mais do que isso, falar sobre esse cinema alenta a possibilidade de resgatar a partir do documentário as vozes desconhecidas dos trabalhadores que construíram e constroem diariamente a realidade que nos circunda, e que frequentemente são apagados de forma sumária no processo de fazer história. Isso evidencia um caráter fundamental da memória histórica: existe um acirrado processo de luta de classes 64 pela história. O processo de escrita sobre a relação entre esses filmes, a história, e o desenvolvimentismo, antes de ser um operação mecânica de simples resgate do que aconteceu no passado, perpassa um esforço de reconstruir ativamente este passado histórico, sempre cientes do fato de que nossa reelaboração do passado histórico está saturado de determinações do nosso presente (BENJAMIN, 1994). Dessa forma, é necessário localizar o presente em que estas considerações estão sendo tecidas, e quais são as perspectivas de futuro que este presente têm nos sugerido. Tomando por empréstimo o trocadilho cunhado pelo sociólogo Francisco de Oliveira a partir da obra clássica de Eduardo Galeano, é uma questão de pensar, atualmente, quais são as vias abertas para a América Latina.

Já no ano de 2005, Francisco de Oliveira já alertava sobre o acirramento das relações de dependência a partir da forma em que capital financeiro se reproduzia na América Latina. Ele localiza até mesmo nos governos mais progressistas oriundos do fenômeno político da Maré Rosa uma tendência a um reformismo conciliatório com preceitos neoliberais, identificando um quadro de estagnação e de retrocessos em termos de direitos civis (OLIVEIRA, 2005). Em 2020, nos encontramos em tal etapa de agudização do processo neoliberal, que até mesmo a etapa do novo-desenvolvimentismo que o Brasil entrava à época em que Francisco de Oliveira escreveu seu ensaio parece uma perspectiva alentadora diante de nosso olhar perplexo ao desmonte das instituições e intensificação do já existente aparelhamento do Estado por interesses financeiros. A combinação entre a rapinagem dessas elites e a escaladas autoritárias do governo de Jair Bolsonaro fazem com que a seguinte frase de Francisco, proferida há 15 anos, soe muito atual: "o capitalismo na periferia está revelando-se totalmente incompatível com a democracia" (OLIVEIRA, 2005, p. 2). Entretanto, a precariedade da conjuntura atual não pode impor uma nostalgia à repetição dos mesmos erros políticos da década passada. 
O novo-desenvolvimentismo, antes de ser um fato incontornável e positivo para um projeto verdadeiramente progressista de país, é fruto de uma lacuna fundamental nos nossos estudos sobre desenvolvimento e dependência, lacuna esta que está mais próxima de um projeto deliberado do que um fato incidental. Como aponta Prado (2010), o ressurgimento do desenvolvimentismo como paradigma orientador da política econômica, mesmo com suas particularidades no Século XXI, pode ser retraçado a um processo que inicia na Década de 1960, com a cisão entre dois setores das correntes dependentistas: as escolas relacionadas à sociologia paulista, encabeçada principalmente por Fernando Henrique Cardoso; e os teóricos marxistas da dependência, como Ruy Mauro Marini, Theotônio dos Santos e Vânia Bambirra. Após o recrudescimento da perseguição política da Ditadura Empresarial-Militar com o Ato Institucional $N^{0} 5$ e com a escalada posterior da presidência de Emílio Garrastazu Médici, houve um processo em que os teóricos marxistas da dependência foram obrigados a exilarem-se em outros países da América Latina enquanto Fernando Henrique Cardoso, a partir de sua influência no Centro Brasileiro de Análise e Planejamento (CEBRAP) não enfrentou grandes obstáculos para a realização de suas pesquisas e estudos, visto que enquanto suas obras possuíam ampla circulação no Brasil, a dos teóricos anteriores eram terminantemente banidas e censuradas. Diante disso, Prado (2010) aponta que ao estabelecer um ponto de vista único sobre dependência no território nacional, cujas críticas à corrente marxista não tinham suas réplicas publicadas e nem suas obras originais divulgadas, a partir do trabalho de Fernando Henrique Cardoso na CEBRAP rebaixou-se o debate sobre a Teoria Marxista da Dependência a um "não-debate". Não incidentalmente, os principais teóricos relacionados a Fernando Henrique Cardoso foram os artífices do novodesenvolvimentismo, tanto no mandato presidencial deste (como é o caso de Luís Bresser Pereira) quanto nos governos petistas (Guido Mantega) e ainda no de Michel
Temer (José Serra).

A ideia de que o caminho para o desenvolvimento é a mera industrialização com política econômica facilitadora de divisas internacionais não se provou apenas incorreta, mas também enganosa. Como bem notaram os teóricos marxistas da dependência, as políticas conciliatórias e submissas da burguesia brasileira com o capital externo resultou num controle sobre a tecnologia industrial brasileira, sobre os setores de exportação, de energia e transporte. Este controle, imposto em decorrência da posição brasileira na divisão internacional do trabalho, é garantido pela existência de monopólios internacionais com níveis elevados de produtividade, que ao estabelecer relações comerciais com países dependentes como o Brasil, acarretam uma transferência de valor. Como bem notou Marini (1973), esse é um dado estrutural na maneira que o capitalismo se configura no América Latina.

Ainda nos vemos numa encruzilhada tal qual aquela posta por Darcy Ribeiro ao teorizar sobre os modelos e perspectivas de universidade e produção de conhecimento na América Latina: entre uma ideologia de modernização reflexa, fruto da consciência ingênua e da importação acrítica de visões de desenvolvimento pouco compatíveis com a materialidade da realidade nacional; e seu par oposto, de uma perspectiva de crescimento autônomo e ancorado na consciência crítica (RIBEIRO, 1978).

Brasília completa 60 anos no ano de 2020, e a memória histórica implora a imputar justiça pelo número de operários explorados e assassinados pelo empreendimento modernizante e faraônico. Concebida como ventre de uma nova civilização, Brasília se mostrou um reflexo das contradições mais venais do capitalismo periférico, e se constituiu como um caso paradigmático da nossa relação com a perspectiva de desenvolvimento. Berman (1982) encontrou em Goethe a metáfora fundacional da modernidade, em que Fausto representaria a grandiosidade das pretensões desenvolvimentistas dos grandes estadistas e o demônio Mefistófeles, 
a rapinagem das elites financeiras - que não obstante sua indiferença ao progresso material e espiritual do ser humano, forjam alianças com seus faustos, originando a grande contradição do conceito de progresso na modernidade: o discurso altivo e pretensamente enobrecedor do progresso e a baixeza das perdas humanas, da exploração e dos abusos que acompanham a empreitada modernizante. A metáfora fáustica encontra um paralelo perfeito na história de Brasília, que surge quase duzentos anos após a obra goethiana. Adaptando a expressão de Berman (1982), talvez Brasília seja essencialmente a amostra latino-americana da tragédia do desenvolvimento.

\section{REFERÊNCIAS}

AS PRIMEIRAS imagens de Brasília. Direção: Jean Manzon. Rio de Janeiro: Atlântida Empresa Cinematográfica do Brasil S.A., 1957. 10 min, p\&b. Disponível em <https:// youtu.be/xnXQQeU5nlk> Acesso em: 27 fev. 2020.

BENJAMIN, Walter. Sobre o conceito de história. In: Magia e técnica, arte e política: ensaios sobre literatura e história da cultura. São Paulo: Editora brasiliense, 1994 (7a ed.), pp. 222-232.

BERMAN, Marshall.Tudo o queésólido desmancha no ar: a aventura da modernidade. São Paulo: Companhia das Letras, 2007

BETHANIA, Maria. Viramundo. Maria Bethânia canta Noel Rosa e Outras Raridades. BMG Brasil Ltda, 1965. Disponível em< https://www.youtube.com/ watch?v=PLOuwMcqQ08> Acesso em: 27 fev. 2020.

BRASÍLIA contradições de uma cidade nova. Direção: Joaquim Pedro de Andrade. Fotografia: Affonso Beato. Rio de Janeiro: Filmes do Serro, 1967.22 min, cor. Disponível em: <https://www.youtube.com/watch?v=zbSPytnX1ao > Acesso em: 27 fev. 2020.

BRASÍLIA segundo Feldman. Direção: Vladimir Carvalho. Fotografia: Eugene Feldman. Rio de Janeiro: CNRC, 1979. 20 min, cor. Disponível em <https://youtu.be/ 68
Q0ut6D2oRz4> Acesso em: 27 fev. 2020.

CARVALHO, Vladimir. Cinema candango: matéria de jornal. Brasília: Cinememória, 2002

CARVALHO, Vladimir. Parte IV - Roteiro reconstituído. In: Conterrâneos velhos de guerra: opinião da crítica e roteiro. Brasília: Governo do Distrito Federal/Secretaria de Cultura e Esporte/Fundação Cultural do DF, 1997, pp. 167-366.

COLUNA Norte. Direção: Jean Manzon. Rio de Janeiro: Jean Manzon Films S.A., 1960. 10 min, p\&b. Disponível em <https://youtu.be/Fo4cLakwurE> Acesso em: 27 fev. 2020.

DOS SANTOS, Theotônio. Desenvolvimento e dependência no pensamento social latino-americano. In: A teoria da dependência: balanço e perspectivas, Rio de Janeiro, Editora Civilização Brasileira, 2000.

FALA Brasília. Direção: Nelson Pereira dos Santos. Fotografia: Dib Lutfi. Rio de Janeiro: INCE, 1966. 13 min, p\&b. Disponível em <https://youtu.be/i5ht8d2IVTU> Acesso em: 27 fev. 2020.

KUBITSCHEK, Juscelino. Discurso de JK na inauguração de Brasília - Brasília, 21 de abril de 1960. In: Discursos selecionados do Presidente Juscelino Kubitschek. Brasília: Fundação Alexandre de Gusmão, 2009, p. 51-53.

MARINI, Ruy Mauro. Dialética da dependência, 1973. In: Ruy Mauro Marini: Vida e obra. São Paulo: Expressão Popular, 2005, p. 137-180. Disponível em <https://www. marxists.org/portugues/marini/1973/mes/dialetica.htm> Acesso em:27 de fev. 2020. MORICONI, Sérgio. Apontamentos para uma história. Brasília: Instituto Terceiro Setor, 2012.

OLIVEIRA, Francisco. Há vias abertas para a América Latina? In: Nova hegemonia mundial: alternativas de mudanças e movimentos sociais. Buenos Aires: CLACSO, 2005, p. 111-118. 
PRADO, Fernando Correa. História de um não-debate: a trajetória da teoria marxista da dependência no Brasil. Comunicação \& Política, v. 29 n. 2, p. 68-94, 2010.

RIBEIRO, Darcy. A universidade necessária. São Paulo: Paz \& Terra, 1978 (3a ed.).

SILVA, Meire Oliveira. Desenvolvimentismo, plano-piloto e segregação: uma análise de Brasília, contradições de uma cidade nova de Joaquim Pedro de Andrade. Revista Rua, v. 25 n. 1, 2019, p. 165-182.

TEIXEIRA, Hermes Aquino. Brasília: o outro lado da utopia (1956-1960). Dissertação (Mestrado em História) - Departamento de Geografia e História da Universidade de Brasília. Brasília, 1982.

XAVIER, Ismail. 0 discurso cinematográfico: a opacidade e a transparência. São Paulo: Editora Paz e Terra, 2005 (3a ed). 